\title{
BMJ Open Mammograms on-the-go-predictors of repeat visits to mobile mammography vans in St Louis, Missouri, USA: a case-control study
}

\author{
Bettina F Drake, ${ }^{1}$ Salmafatima S Abadin, ${ }^{1}$ Sarah Lyons, ${ }^{1}$ Su-Hsin Chang, ${ }^{1}$ \\ Lauren T Steward, ${ }^{1}$ Susan Kraenzle, ${ }^{2,3,4}$ Melody S Goodman ${ }^{1}$
}

To cite: Drake BF, Abadin SS, Lyons S, et al. Mammograms on-the-go-predictors of repeat visits to mobile mammography vans in St Louis, Missouri, USA: a case-control study. BMJ Open 2015;5:e006960. doi:10.1136/bmjopen-2014006960

- Prepublication history for this paper is available online. To view these files please visit the journal online (http://dx.doi.org/10.1136/ bmjopen-2014-006960).

Received 20 October 2014 Revised 7 January 2015 Accepted 18 January 2015

CrossMark

\footnotetext{
${ }^{1}$ Division of Public Health Sciences, Department of Surgery, Washington University in St Louis School of Medicine, St Louis,

Missouri, USA

2Joanne Knight Breast Health Center, St Louis, Missouri, USA

${ }^{3}$ The Alvin J Siteman Cancer Center at Barnes-Jewish Hospital, St Louis, Missouri, USA

${ }^{4}$ Washington University School of Medicine, St Louis, Missouri, USA
}

Correspondence to Dr Bettina F Drake; drakeb@wustl.edu

\section{ABSTRACT}

Objectives: Among women, breast cancer is the most common non-cutaneous cancer and second most common cause of cancer-related death. The purpose of this study was to determine the extent to which women use mobile mammography vans for breast cancer screening and what factors are associated with repeat visits to these vans.

Design: A case-control study. Cases are women who had a repeat visit to the mammography van. $(n=2134)$.

Participants: Women who received a mammogram as part of Siteman Cancer Center's Breast Health Outreach Program responded to surveys and provided access to their clinical records $(\mathrm{N}=8450)$. Only visits from 2006 to 2014 to the mammography van were included.

Outcome measures: The main outcome is having a repeat visit to the mammography van. Among the participants, $25.3 \%(N=2134)$ had multiple visits to the mobile mammography van. Data were analysed using $\chi^{2}$ tests, logistic regression and negative binomial regression.

Results: Women who were aged 50-65, uninsured, or African-American had higher odds of a repeat visit to the mobile mammography van compared with women who were aged 40-50, insured, or Caucasian (OR=1.135, 95\% $\mathrm{Cl} 1.013$ to $1.271 ; \mathrm{OR}=1.302,95 \%$ $\mathrm{Cl} 1.146$ to $1.479 ; \mathrm{OR}=1.281,95 \% \mathrm{Cl} 1.125$ to 1.457 ), respectively. However, the odds of having a repeat visit to the van were lower among women who reported a rural ZIP code or were unemployed compared with women who provided a suburban ZIP code or were employed ( $\mathrm{OR}=0.503,95 \% \mathrm{Cl} 0.411$ to 0.616 ; $\mathrm{OR}=.868,95 \% \mathrm{Cl} 0.774$ to 0.972 ), respectively.

Conclusion: This study has identified key characteristics of women who are either more or less likely to use mobile mammography vans as their primary source of medical care for breast cancer screening and have repeat visits.

\section{INTRODUCTION}

In the USA, one in eight women develop an invasive form of breast cancer in their

\section{Strengths and limitations of this study}

- This study has identified key characteristics of women who are either more or less likely to use mobile mammography vans as their primary source of medical care for breast cancer screening and have repeat visits.

- These data can be generalisable to other mobile units that service urban, suburban and rural environments with a similar population.

- The present research study adds insight into a new strategy that uses mobile mammography as an outreach strategy for repeat screening in minority and medically underserved communities.

- Owing to differences in breast cancer screening guidelines, our use of American Cancer Society (ACS) mammography guidelines is not generalisable to populations whose screening guidelines differ.

- The reasons why women missed routine screening were not investigated in our study.

- It is possible that women in our study had a repeat mammogram at another facility that is not captured in our data, and thus were adherent to screening guidelines by using multiple points of service.

lifetime, making it the most common cancer after skin cancer among women. ${ }^{1}$ There were 232640 new cases of invasive breast cancer diagnosed in addition to 62570 cases of non-invasive breast cancer in $2014 .{ }^{1}$ Although breast cancer is the second leading cause of cancer death in women, the mortality rate has been on the decline since the late $1980 \mathrm{~s} .{ }^{1}$ The decreases in mortality rate due to breast cancer can be attributed to mammography screening, increased awareness and advancements in treatment. ${ }^{1}{ }^{2}$

Mammography screening is a tool used to detect breast cancer in its earliest stages so that treatment can be initiated promptly, and it has led to improved survival rates among 
women older than 40 years of age but most significantly in those over the age of 50 years. ${ }^{2-4}$ According to the American Cancer Society (ACS), women who are in good health and at least 40 years old should get a mammogram annually. ${ }^{1}$ Mammography screening rates have remained at $67 \%$ over the past several years ${ }^{5}$ with the repeat screening rate in the overall population in the US at 46\%. ${ }^{6}$ However, screening rates among uninsured women are dramatically lower at $31.5 \%$ in $2010 .^{5}$ Women who are not being screened regularly tend to be a part of underserved populations and are disproportionately affected by breast cancer. ${ }^{7}$

In order to improve screening rates, particularly among women who underuse mammography screening, many areas, rural and urban, have introduced mobile mammography. In a study conducted by Brooks $\mathrm{et} a l^{8}$ the rate of detection of breast tumours by mobile mammography was significantly higher than the age-adjusted rate of the general population, and $68 \%$ of those diagnosed by mobile mammography were uninsured. This suggests that mobile mammography may be detecting many tumours that otherwise could have gone undiscovered. Even further, mobile mammography has been shown to be accurate and accessible,,${ }^{9} 10$ thereby increasing participation rates and improving equity of care. ${ }^{11}$ Interestingly, in a study conducted by Lee and Yao ${ }^{12}, 21.3 \%$ of the women surveyed preferred mobile mammography for screening while $7.6 \%$ favoured a hospital setting.

With the increasing presence of mobile mammography, several studies have assessed self-reported adherence to screening guidelines at the time of participation in mobile mammography. Brooks et $a l^{8}$ found that $29 \%$ of the women participating in the mobile mammography screenings had either never been screened or not screened within the past 5 years while Vyas $e t a l^{13}$ discovered that $46.2 \%$ of the women obtaining a mobile mammogram had a screening mammogram in the past 2 years. Mobile mammography is reaching higher risk women who are taking advantage of the increased opportunities for screening. However, there is a lack of research in determining if women are using mobile mammography for multiple or consecutive screening visits.

The Alvin J Siteman Cancer Center (SCC) at BarnesJewish Hospital and Washington University School of Medicine in St Louis, Missouri, has offered mammograms at little or no cost for women through their mobile mammography van (MMV) service for the past 10 years. ${ }^{14}$ The rate of mammography screening in Missouri exceeds national estimates at $72.9 \%$, but women earning less than $\$ 25000$ annually had significantly fewer mammograms than women whose annual income is at least $\$ 25000 .{ }^{15}$ Even further, for women earning less than \$25000 per year in Missouri, over one-third are without healthcare coverage, making it difficult for them to seek primary care and obtain screening. ${ }^{15}$ In 2006, the Mammography Outreach Registry was created and any woman who qualified for financial assistance to obtain a mammogram at the Joanne Knight
Breast Health Center or at the MMV was included. Participation in the registry was not required for receipt of services, but the vast majority of women (approximately $99 \%$ ) who qualified for the programme agreed to participate. The purpose of this study was to use data from the Mammography Outreach Registry to determine the extent to which women use MMVs for breast cancer screening and what factors are associated with repeat visits to these vans.

\section{METHODS}

\section{Study sample}

This study used a Mammography Outreach Registry that collected patient and questionnaire data from women who have utilised the mammography services provided on the SCG MMV. Participants provided consent and questionnaires were administered by a research technician to all women who receive financial assistance for a mammogram on the van prior to receiving a mammogram. This analysis included women who had at least one screening visit on the van between April 2006 and March 2014 (N=9480). Since the overwhelming majority of the SCC MMV population were African-American and Caucasian $(89.26 \%$ ), we excluded women of other races. Our study sample included 8450 respondents who met our inclusion criteria. No follow-up data are presented in this analysis.

\section{Variable definitions}

A repeat visit was defined as the number of times a woman returned to the SCC MMV after her initial visit. Repeat visits were assessed as a dichotomous variable: those with only one visit (no repeat) and those with two or more visits (repeat). The number of visits ranged from 1 to 7 . Demographic variables were collected from the survey administered at the time of the screening and the women's health records. Covariates selected for analyses included insurance status (insured vs non-insured), age $(<40,40-50,50-65,65+)$, race (Caucasian vs African-American), marital status (married vs not married) and employment status (employed vs not employed). The ZIP code of each participant was used to determine urban status. Urban status was divided into three categories (urban, suburban and rural). ZIP codes from St Louis city were classified as urban, ZIP codes from St Louis County were classified as suburban, and rural was classified as ZIP codes coming from the Bootheel region of Missouri. On the questionnaire (administered at the time of each visit), participants were asked about the quality of their mammography experience. Response options were Very Bad, Okay, Good and Great. The response to this question from each participant's first visit was used in the analysis.

\section{Statistical analysis}

Bivariate analyses were conducted using the two outcome measures (discrete and dichotomous repeat 
visits) separately and comparing them to all of the demographic factors of interest. Logistic regression was used for the dichotomous outcome (repeat visit vs no repeat visit) to model the likelihood of a woman having a repeat visit on the SCC MMV according to potential predictors. ORs were calculated for each of the significant predictors. Statistical analysis was conducted using SAS software (V.9.4, SAS Institute, Cary, North Carolina, USA); significance was assessed at $\alpha<0.05$. To determine if we could isolate predictive factors for increased number of visits, we employed a negative binomial regression model using the number of repeat visits as the outcome. A negative binomial model was used because the outcome was count data and the majority of participants had no repeat visits. ${ }^{16}$ Missing data were minimal. In total, $8.35 \%$ of data were missing for Models 1 and 2. Per cent missing for each variable is shown in table 1 .
In subanalyses, we calculated the number of consecutive visits among women with repeat visits. Variables were added into the logistic and negative binomial models if they retained a significance at the $\alpha<0.1$ level in bivariate analyses. In both models, we controlled for the varying length of time that women could potentially have had a repeat visit by controlling for year of first visit.

\section{RESULTS}

Among the 8450 study participants, 25\% ( $\mathrm{N}=2101)$ had multiple visits to the MMV and of these women, $41 \%$ always had consecutive visits. The mean number of repeat visits was 2.5. Descriptive statistics and $\chi^{2}$ analyses are reported in table 1 . There was a significant difference between women with no repeat visits versus women with repeat visits by urban status, insurance coverage,

\begin{tabular}{|c|c|c|c|c|c|}
\hline & \multicolumn{2}{|c|}{ No repeats $(n=6349)$} & \multicolumn{2}{|c|}{ Repeats ( $n=2101)$} & \multirow[b]{2}{*}{ p Value } \\
\hline & $\bar{n}$ & per cent & $\bar{n}$ & per cent & \\
\hline Mean repeat visits & - & - & 2.49 & - & - \\
\hline \multicolumn{6}{|l|}{ Consecutive visits } \\
\hline Always & - & - & 865 & 41.17 & \\
\hline Sometimes & - & - & 392 & 18.66 & \\
\hline Never & - & - & 844 & 40.17 & \\
\hline Urban status & & & & & $<0.0001^{*}$ \\
\hline Urban & 2776 & 43.72 & 1012 & 48.17 & \\
\hline Suburban & 2483 & 39.11 & 881 & 41.93 & \\
\hline Rural & 975 & 15.36 & 196 & 9.33 & \\
\hline Missing & 115 & 1.81 & 12 & 0.57 & \\
\hline Insurance coverage & & & & & $<0.0002^{*}$ \\
\hline Yes & 2130 & 33.55 & 610 & 29.03 & \\
\hline No & 4218 & 66.44 & 1487 & 70.78 & \\
\hline Missing & 1 & 0.02 & 4 & 0.19 & \\
\hline Age group & & & & & $0.0023^{*}$ \\
\hline Under 40 & 68 & 1.07 & 7 & 0.33 & \\
\hline $40-50$ & 2668 & 42.02 & 833 & 39.65 & \\
\hline $50-65$ & 3098 & 48.80 & 1081 & 51.45 & \\
\hline Over 65 & 513 & 8.08 & 180 & 8.57 & \\
\hline Missing & 2 & 0.03 & 0 & 0.00 & \\
\hline Race & & & & & $<0.0001^{*}$ \\
\hline Caucasian & 2556 & 40.26 & 638 & 30.37 & \\
\hline African-American & 3793 & 59.74 & 1463 & 69.93 & \\
\hline Marital status & & & & & $<0.0001^{*}$ \\
\hline Not currently married & 4338 & 68.33 & 1606 & 76.44 & \\
\hline Married & 1580 & 24.89 & 450 & 21.42 & \\
\hline Missing & 431 & 6.79 & 45 & 2.14 & \\
\hline Baseline mammography experience & & & & & $0.0036^{\star}$ \\
\hline Very bad & 19 & 0.30 & 14 & 0.67 & \\
\hline Okay & 492 & 7.75 & 185 & 8.81 & \\
\hline Good & 3547 & 55.87 & 1205 & 57.35 & \\
\hline Great & 2196 & 34.59 & 656 & 31.22 & \\
\hline Missing & 95 & 1.50 & 41 & 1.95 & \\
\hline Employed & & & & & $0.0003^{*}$ \\
\hline Yes & 2074 & 32.67 & 776 & 36.93 & \\
\hline No/missing & 4275 & 67.33 & 1325 & 63.07 & \\
\hline
\end{tabular}


Table 2 Logistic regression model

\begin{tabular}{|c|c|c|c|c|c|c|}
\hline & \multicolumn{3}{|c|}{ Model $1^{*}$} & \multicolumn{3}{|c|}{ Model 2† } \\
\hline & $\overline{\text { OR }}$ & $95 \% \mathrm{Cl}$ & p Value & OR & $95 \% \mathrm{Cl}$ & p Value \\
\hline \multicolumn{7}{|l|}{ Urban status } \\
\hline Suburban & Ref & - & - & Ref & - & - \\
\hline Urban & 1.027 & 0.925 to 1.142 & 0.6142 & 1.116 & 0.995 to 1.142 & 0.0610 \\
\hline Rural & 0.567 & 0.477 to 0.673 & $<0.0001$ & 0.488 & 0.398 to 0.598 & $<0.0001$ \\
\hline \multicolumn{7}{|l|}{ Insurance coverage } \\
\hline Yes & Ref & - & - & Ref & - & - \\
\hline No & 1.231 & 1.102 to 1.371 & 0.0002 & 1.319 & 1.160 to 1.500 & $<0.0001$ \\
\hline \multicolumn{7}{|l|}{ Age group } \\
\hline Under 40 & 0.330 & 0.151 to 0.721 & 0.0054 & 0.335 & 0.149 to 0.752 & 0.0080 \\
\hline $40-50$ & Ref & - & - & Ref & - & - \\
\hline $50-65$ & 1.118 & 1.007 to 1.240 & 0.0364 & 1.150 & 1.026 to 1.289 & 0.0163 \\
\hline Over 65 & 1.124 & 0.932 to 1.355 & $<0.0001$ & 1.160 & 0.925 to 1.454 & 0.1980 \\
\hline \multicolumn{7}{|l|}{ Race } \\
\hline Caucasian & Ref & - & - & Ref & - & - \\
\hline African-American & 1.545 & 1.390 to 1.717 & $<0.0001$ & 1.261 & 1.108 to 1.436 & 0.0005 \\
\hline \multicolumn{7}{|l|}{ Marital status } \\
\hline Married & Ref & - & - & Ref & - & - \\
\hline Not currently married & 1.300 & 1.154 to 1.465 & $<0.0001$ & 1.105 & 0.968 to 1.262 & 0.1379 \\
\hline \multicolumn{7}{|c|}{ Baseline mammography experience } \\
\hline Very bad & 2.171 & 1.085 to 4.343 & 0.0284 & 1.544 & 0.739 to 3.224 & 0.2475 \\
\hline Okay & 1.107 & 0.923 to 1.327 & 0.2723 & 0.948 & 0.780 to 1.152 & 0.5907 \\
\hline Good & Ref & - & - & Ref & - & - \\
\hline Great & 0.879 & 0.789 to 0.987 & 0.0207 & 0.974 & 0.866 to 1.096 & 0.6652 \\
\hline \multicolumn{7}{|l|}{ Employed } \\
\hline Yes & Ref & - & - & Ref & - & - \\
\hline No & 0.828 & 0.747 to 0.918 & 0.0003 & 0.857 & 0.765 to 0.961 & 0.0084 \\
\hline Year at first screening & 0.681 & 0.661 to 0.703 & $<0.0001$ & 0.664 & 0.643 to 0.687 & $<0.0001$ \\
\hline
\end{tabular}

age group, race, marital status, baseline mammography experience and employment.

In the logistic regression model (table 2), women who were aged 50-65, uninsured, or African-American had higher odds of a repeat visit to the MMV compared with women who were aged 40-50, insured, or Caucasian, respectively $\quad(\mathrm{OR}=1.150,95 \%$ CI 1.026 to 1.289 ; $\mathrm{OR}=1.319,95 \%$ CI 1.160 to $1.500 ; \mathrm{OR}=1.261,95 \%$ CI 1.108 to 1.436$)$. However, the odds of having a repeat visit to the van was lower among women who reside in a rural ZIP code, were under 40 years old, or were unemployed, compared with women who reside in a suburban ZIP code, were aged 40-50, or were employed, respectively $\quad(\mathrm{OR}=0.488, \quad 95 \% \quad \mathrm{CI} \quad 0.398$ to 0.598 ; $\mathrm{OR}=0.335,95 \%$ CI 0.149 to $0.752 ; \mathrm{OR}=0.857,95 \%$ CI 0.765 to 0.961$)$.

Results from negative binomial regression analyses (table 3) suggest that women who were 50-65 years old, uninsured, or African-American had a statistically significant higher number of repeat visits to the MMV compared with those $40-50$ years old, insured, or Caucasian, respectively $(\beta=0.15,95 \%$ CI 0.06 to $0.24 ; \beta=0.17,95 \%$ CI 0.07 to $0.27 ; \beta=0.21,95 \%$ CI 0.10 to 0.31 ). On the other hand, residing in a rural ZIP code, being under 40 years old, or being unemployed were statistically significant predictors of a lower number of repeat visits to the MMV compared with residing in a suburban ZIP code, being $40-50$ years old, or being employed, respectively ( $\beta-0.6180,95 \%$ CI -0.7871 to $-0.4489 ; \beta-0.9125$, $95 \%$ CI -1.6180 to $-0.2070 ; \beta-0.1638,95 \%$ CI -0.2545 to -0.0731 ).

To determine whether women with a repeat mammography were following up an abnormal mammography result, the investigators conducted the same analyses only among women with a negative mammography result (Breast Imaging Reporting and Database System $(B I-R A D)=1)$ and the results were similar to what is presented here. These results are not shown.

\section{DISCUSSION}

Of the women who have had repeat visits to the MMV, $41 \%$ had all of their visits within 1 year of each other, adhering to ACS recommended screening guidelines. Women who are aged 50-65, uninsured, or AfricanAmerican are more likely to undergo a repeat visit to the MMV whereas those less likely to have a repeat visit are unemployed or reside in a rural ZIP code.

The findings demonstrate that the MMV has had considerable success servicing more than half of its 
Table 3 Negative binomial regression model

\begin{tabular}{|c|c|c|c|c|c|c|}
\hline & \multicolumn{3}{|l|}{ Model 1* } & \multicolumn{3}{|l|}{ Model 2† } \\
\hline & Coefficient & $95 \% \mathrm{Cl}$ & p Value & Coefficient & $95 \% \mathrm{Cl}$ & p Value \\
\hline \multicolumn{7}{|l|}{ Urban status } \\
\hline Suburban & Ref & - & - & Ref & - & - \\
\hline Urban & -0.0087 & -0.1030 to 0.0856 & 0.8567 & 0.0659 & -0.0250 to 0.1569 & 0.1552 \\
\hline Rural & -0.5804 & -0.7374 to -0.4235 & $<0.0001$ & -0.6180 & -0.7871 to -0.4489 & $<0.0001$ \\
\hline \multicolumn{7}{|l|}{ Insurance coverage } \\
\hline Yes & Ref & - & - & Ref & - & - \\
\hline No & 0.1292 & 0.0321 to 0.2263 & 0.0091 & 0.1700 & 0.0667 to 0.2732 & 0.0012 \\
\hline \multicolumn{7}{|l|}{ Age group } \\
\hline Under 40 & -1.0512 & -1.7712 to -0.3312 & 0.0042 & -0.9125 & -1.6180 to 0.2070 & 0.0112 \\
\hline $40-50$ & Ref & - & - & Ref & - & - \\
\hline $50-65$ & 0.1367 & 0.0422 to 0.2313 & 0.0046 & 0.1521 & 0.0605 to 0.2437 & 0.0011 \\
\hline Over 65 & 0.1628 & -0.0049 to 0.3306 & 0.0571 & 0.1784 & -0.0004 to 0.3571 & 0.0506 \\
\hline \multicolumn{7}{|l|}{ Race } \\
\hline Caucasian & Ref & - & - & Ref & - & - \\
\hline African-American & 0.4370 & 0.3411 to 0.5329 & $<0.0001$ & 0.2095 & 0.1045 to 0.3144 & $<0.0001$ \\
\hline \multicolumn{7}{|l|}{ Marital status } \\
\hline Married & Ref & - & - & Ref & - & - \\
\hline Not currently married & 0.2468 & 0.1392 to 0.3544 & $<0.0001$ & 0.0859 & -0.0215 to 0.1933 & 0.1168 \\
\hline \multicolumn{7}{|c|}{ Baseline mammography experience } \\
\hline Very bad & 0.4834 & -0.1440 to 1.1109 & 0.1310 & 0.1455 & -0.4104 to 0.7014 & 0.6080 \\
\hline Okay & 0.1535 & -0.0084 to 0.3154 & 0.0631 & -0.0033 & -0.1543 to 0.1476 & 0.9655 \\
\hline Good & Ref & - & - & Ref & - & - \\
\hline Great & -0.0840 & -0.1828 to 0.0147 & 0.0954 & 0.0128 & -0.0816 to 0.1072 & 0.7897 \\
\hline \multicolumn{7}{|l|}{ Employed } \\
\hline Yes & Ref & - & - & Ref & - & - \\
\hline No & -0.2147 & -0.3074 to -0.1219 & $<0.0001$ & -0.1638 & -0.2545 to -0.0731 & 0.0004 \\
\hline Year at first screening & -0.3961 & -0.4234 to -0.3688 & $<0.0001$ & -0.4017 & -0.4298 to -0.3737 & $<0.0001$ \\
\hline
\end{tabular}

vulnerable patient population on a repeat basis. Demographic characteristics of women who are either more or less likely to use mobile mammography services were identified. It is important that mobile mammography is maintained and remains easily accessible to women who continuously use the service.

Although not focused on mobile mammography, previous studies have discovered similar findings in regard to repeat mammography. This study is among the first to assess predictors of repeat screening visits using only mobile mammography. Ulcickas Yood et $a l^{17}$ found that among women 50-74 years old with a normal mammogram, $66 \%$ received another mammogram within 2 years of the initial screening and $88 \%$ did so within 5 years. Even further, Gjelsvik et $a l^{18}$ demonstrated that low use of mammography is quite prevalent among the uninsured; identifying these women better informs development and structuring of a mobile mammography intervention. The results of their analysis suggest that being 55-80 years old, having a primary care doctor and earning an annual income of $\$ 75000$ or more makes a woman more likely to have repeat screening. ${ }^{18}$ In Halabi et $a l \mathrm{~s}^{19}$ study, they concluded that about $50 \%$ of the women in their sample were either categorised as off schedule for screening or never screened in the past.
Off-schedule women may be the most interesting to further investigate because they, in fact, may belong to the group least knowledgeable about screening guidelines but perhaps more likely to return to routine screening. ${ }^{19}$ Although our large sample size may drive some of the statistically significant associations reported here, its public health relevance to mobile mammography programmes is relevant. Our study suggests that women identified as being less likely to have repeat or routine screening in previous studies are significantly more likely to have repeat visits using mobile mammography.

There are limitations to the study. In general, it is difficult to assess repeat mammography rates because they are defined differently among recommended guidelines. ${ }^{5}{ }^{20}$ Second, the reasons why some women missed routine screening were not investigated in our study and it is possible that those women had a mammogram at another facility that is not captured in our data, and thus were adherent to screening guidelines by using multiple points of service. Related to this is that we only assessed mammography screening that occurred on the MMV and women may have had a repeat or consecutive visit on-site instead of at the mobile unit. Finally, generalisability is limited because the sample does not 
proportionally represent all women at risk for breast cancer. However, this sample is representative of the SCC mammography outreach population. In addition, these data can be generalisable to other mobile units that service urban, suburban and rural environments with a similar population.

Further research should uncover ways to make mobile mammography a more effective resource for women who are more likely to use it for routine screening. Future work should also examine how community partnerships and development of a regular van schedule contribute to successful outreach efforts. Mobile mammography users should be surveyed about other factors such as primary care access and social support. Beyond looking at age, race and insurance status as predictors of repeat mammography, several studies have noted other reasons that may explain increased motivation to undergo repeat mammography. Researchers have discussed the importance of social support and integration as well as social networks in encouraging women to seek screening for breast cancer. ${ }^{21}{ }^{22}$ Other studies have also determined that if women have a primary care doctor or other healthcare professional who can provide recommendations or scheduling assistance, they will be more likely to follow screening guidelines. ${ }^{18} 23$

The present research study adds insight into a new strategy that uses mobile mammography as an outreach strategy for repeat screening in minority and medically underserved communities. We now have a better understanding of who is using mobile mammography to adhere to recommended screening guidelines and can begin to find ways to reach these populations more effectively, which will ultimately impact disparities in stage at diagnosis.

Acknowledgements The authors would like to thank the St Louis Affiliate of Susan G Komen for the Cure, the Show Me Healthy Women initiative, and the Program for the Elimination of Cancer Disparities of the Siteman Cancer Center at Barnes-Jewish Hospital and Washington University School of Medicine for their support. They would also like to thank Graham Colditz, $\mathrm{MD}, \mathrm{DrPH}$, for his overall support for this initiative.

Contributors BFD and SL contributed to the conception and design. MSG contributed to the acquisition of data. BFD, SL and MSG contributed to the analysis and interpretation of the data. BFD, SSA and SL contributed to the drafting of the manuscript. BFD, SAA, S-HC, SL, LTS, MSG and SK contributed to the revisions of the manuscript and the interpretation of the findings.

Funding The work of BFD, MSG and S-HC is supported by the Foundation for Barnes-Jewish Hospital and the Alvin J Siteman Cancer Center. BFD and MSG are also supported by NIH via a National Cancer Institute (NCl) Grant U54CA153460-01 and U01 CA114594-01. S-HC is supported by the Agency for Healthcare Research and Quality (AHRQ) Grant K01 HS022330 and NCI Grant U54 CA155496.

Competing interests None.

Ethics approval This study was approved by the Institutional Review Board at Washington University.

Provenance and peer review Not commissioned; externally peer reviewed.

Data sharing statement No additional are data available.
Open Access This is an Open Access article distributed in accordance with the Creative Commons Attribution Non Commercial (CC BY-NC 4.0) license, which permits others to distribute, remix, adapt, build upon this work noncommercially, and license their derivative works on different terms, provided the original work is properly cited and the use is non-commercial. See: http:// creativecommons.org/licenses/by-nc/4.0/

\section{REFERENCES}

1. Society AC. Cancer facts \& figures 2014. Atlanta: American Cancer Society, 2014

2. Nelson HD, Tyne K, Naik A, et al. Screening for breast cancer: an update for the U.S. Preventive Services Task Force. Ann Intern Med 2009;151:727-37, W237-42.

3. Ekwueme DU, Hall IJ, Richardson LC, et al. Estimating personal costs incurred by a woman participating in mammography screening in the National Breast and Cervical Cancer Early Detection Program. Cancer 2008;113:592-601.

4. Health NClatNIo. FactSheet: Mammograms, 2014.

5. American Cancer Society. Cancer prevention \& early detection: facts \& figures 2013. Atlanta, GA: American Cancer Society, 2013.

6. Clark MA, Bonacore LB, Rakowski W. Repeat mammography: prevalence estimates and considerations for assessment. Ann of Behav Med 2003:26:201-11.

7. Prevention CfDCa. Breast cancer rates by race and ethnicity. Atlanta, GA: Centers for Disease Control and Prevention, U.S. Department of Health and Human Services, 2011, 2010.

8. Brooks S, Hembree T, Shelton B, et al. Mobile mammography in underserved populations: analysis of outcomes of 3,923 women. $J$ Community Health 2013;38:900-6.

9. Zelle SG, Vidaurre T, Abugattas JE, et al. Cost-effectiveness analysis of breast cancer control interventions in Peru. PLOS ONE 2013;8:e82575.

10. Hughes JP, Jose DC, Tuch GH, et al. Is Step down assessment of screen-detected lesions as safe as workup at a Metropolitan Assessment Centre? Aust N Z J Public Health 2014;38:44-8.

11. Fontenoy $\mathrm{AM}$, Langlois $\mathrm{A}$, Chang $\mathrm{SL}$, et al. Contribution and performance of mobile units in an organized mammography screening program. Can J Public Health 2013;104:e193-9.

12. Lee $\mathrm{Y}-\mathrm{M}, \mathrm{Yao} \mathrm{H}-\mathrm{H}$. Demographic factors influencing consensus opinion on the recall for women screened by mobile mammography unit in Taiwan. Iran J Radiol 2013;10:116-21.

13. Vyas A, Madhavan S, LeMasters T, et al. Factors influencing adherence to mammography screening guidelines in Appalachian women participating in a mobile mammography program. $J$ Community Health 2012;37:632-46.

14. Fayanju OM, Jeffe DB, Elmore L, et al. Patient and process factors associated with late-stage breast cancer diagnosis in Safety-Net patients: a pilot prospective study. Ann Surg Oncol 2013;20:723-32.

15. 2012 Missouri Behavioral Risk Factor Surveillance System Key Findings. Jefferson City, MO: Missouri Department of Health and Senior Services Office of Epidemiology, 2013.

16. Introduction to SAS. UCLA: Statistical Consulting Group. http://www. ats.ucla.edu/stat/sas/notes2/ (accessed 18 Aug 2014).

17. Ulcickas Yood M, McCarthy BD, Lee NC, et al. Patterns and characteristics of repeat mammography among women 50 years and older. Cancer Epidemiol Biomarkers Prev 1999;8:595-9.

18. Gjelsvik A, Rogers ML, Clark MA, et al. Continuum of mammography use among US women: classification tree analysis. Am J Health Behav 2014;38:492-500.

19. Halabi S, Skinner CS, Samsa GP, et al. Factors associated with repeat mammography screening. J Fam Pract 2000;49:1104-12.

20. Force USPST. Screening for breast cancer: U.S. Preventive Services Task Force recommendation statement. Ann Intern Med 2009;151:716-26, W-236.

21. Moudatsou MM, Kritsotakis G, Alegakis AK, et al. Social capital and adherence to cervical and breast cancer screening guidelines: a cross-sectional study in rural Crete. Health Soc Care Community 2014;22:395-404.

22. Lagerlund M, Sontrop JM, Zackrisson S. Psychosocial factors and attendance at a population-based mammography screening program in a cohort of Swedish women. BMC Womens Health 2014:14:33.

23. Davis T, Rademaker A, Bennett C, et al. Improving mammography screening among the medically underserved. J Gen Intern Med 2014:29:628-35. 